1 Response of benthic assemblages to multiple stressors: comparative effects of nutrient

2

3

4

5

6

7

8

9

\title{
enrichment and physical disturbance
}

Joseph M. Kenworthy ${ }^{1,2 *}$, David M. Paterson ${ }^{1}$ and Melanie J. Bishop ${ }^{2}$

${ }^{1}$ Sediment Ecology Research Group; Scottish Oceans Institute, University of St Andrews, East Sands, St. Andrews, Fife, KY16 8LB, UK

2Department of Biological Sciences, Macquarie University, North Ryde NSW, 2109, Australia

*Corresponding author: joseph.kenworthy@sb.roscoff.fr

Abstract

Stressors to ecological communities often overlap in time and space and may have additive, synergistic or antagonistic effects. Nutrient enrichment and physical disturbance are two commonly co-occurring stressors to estuarine ecosystems, but their combined effects have mainly been investigated in mesocosm experiments of unknown relevance to field scenarios. Here, the interacting effects of these two stressors were examined at two field locations - Botany Bay and Lane Cove, New South Wales, Australia - using a fully orthogonal manipulative experiment. All possible combinations of zero, low and high intensities of nutrient enrichment and physical disturbance on macrofaunal and microphytobenthic communities were examined. Effects of stressors were generally site-specific and additive, differing in terms of magnitude of effects, 
although some idiosyncratic interactive effects were seen on selected species. Where effects of stressors were observed, nutrient enrichment generally increased microphytobenthic biomass and altered the macrofaunal community structure while physical disturbance produced limited impacts. The divergent results of this and previous mesocosm experiments, which found primarily interactive effects of the stressors, highlights the importance of undertaking field experiments that offer a greater element of realism. Furthermore, this study, in finding differing responses to stressors at the two sites, highlights the importance of environmental context in mediating effects.

\section{Key words:}

Multiple Stressors; Context dependence; Nutrient Enrichment; Disturbance; Macrobenthos, Microphytobenthos, Field Experiments

\section{Introduction}

How organisms respond to naturally occurring and anthropogenic stressors has been a subject that has dominated the marine ecological literature for many decades (Dayton 1971, Connell 1978, Paine \& Levin 1981, Menge \& Sutherland 1987, Hall 1994, Crain et al. 2008). Early studies considered the effects of stressors independently from one another and on individual species, yet stressors to natural ecological systems rarely occur singularly (Crain et al. 2008, Halpern et al. 2008) and species rarely occur alone. Effects of multiple stressors cannot easily be predicted from the effects of singular stressors because, when combined, they are rarely neutral but have additive, subtractive or synergistic effects (Crain et al. 2008, Darling \& Côté 2008, Bijma et al. 2013). Yet many studies continue to examine the effects of stressors individually and on single 
species or small sub groups of taxa (Crain et al. 2008). As coastal development and climate change continue to increase the frequency and intensity of stressors (Halpern et al. 2008, Bijma et al. 2013) there is need to understand the combined effects of stressors, so as to develop appropriate policy and management strategies to manage and perhaps minimise their impact.

Of the studies that have considered the effects of multiple stressors on organisms, many have been conducted in the controlled environment of experimental mesocosms, with species isolated from their habitats and communities (Hicks et al. 2011, Godbold et al. 2011). Although such studies allow the effects of stressors to be examined in the absence of other confounding influences, the extent to which results can be applied to natural systems is unclear because they fail to take into consideration the role of the environmental and biotic context in mediating stressor impacts. For example, organisms can make use of microhabitats to minimise exposure to stressors (Jones \& Boulding 1999) and, under natural conditions, ecological interactions such as competition, facilitation and predation may dampen or exacerbate stressor impacts (Christensen et al. 2006, Hicks et al. 2011). In situ mesocosms have been used effectively to add an element of realism to assessments of stressor impacts (e.g. Christensen et al. 2006). Nevertheless, while studies such as these offer interesting insights and explore important relationships between changes in ecosystem function and biodiversity under scenarios of environmental change, they do not represent natural conditions and field studies are still needed as part of the experimental framework (for a review of the topic see Crain et al. 2008; Przeslawski et al. 2015 and references therein). 
Estuarine environments are among the most heavily impacted in the world, with greater than $40 \%$ of the world's human population living within $100 \mathrm{~km}$ of the coast. Among the plethora of stressors affecting these systems on a daily basis, nutrient enrichment and physical disturbances of sediments are often singled out as the most severe (Gray 1997). Leaching of nutrients from the terrestrial environment, atmospheric deposition and decomposition are natural sources of nutrient loading in these environments but these can become exacerbated by human influences (Nixon 1995). For example, the discharge of sewage into aquatic environments, as well as run-off of nutrient-rich fertilisers, cleaning products and animal wastes from the land can enhance delivery of nitrogen and phosphorus to estuarine systems (Nixon 1995, Vitousek et al. 1997a). Where nitrogen and/or phosphorous is a limiting resource, addition of these nutrients has the potential to greatly stimulate primary productivity (Vitousek et al. 1997a, Cloern 2001). Excess nutrients have been linked to eutrophication events worldwide whereby algal blooms are facilitated, ultimately leading to hypoxic and anoxic conditions through over-stimulation of oxygen-consuming microbial decomposition (Vitousek et al. 1997b).

High human population densities around estuaries also facilitate many small scale disturbances to estuarine sediments through recreation - e.g. boat wake, anchorage, propeller scarring, coastal walking (Bishop 2005, Rossi et al. 2007) - and as a consequence of livelihood exploitation - e.g. bait digging, fishing, dredging (Wynberg \& Branch 1994, Somerfield et al. 1995, Brown \& Wilson 1997). These physical disturbances have been widely studied and can lead to the disturbance and redistribution of sediments (Hall 1994). Such disturbances are likely to cause physical damage to sediment-dwelling organisms or burrows (Hall \& Harding 1997). This physical disturbance has the 
potential to alter the distribution, abundance and diversity of macrofaunal assemblages (Fraterrigo \& Rusak 2008). At a larger scale, natural events such as storms also cause physical disturbances to sediments although less frequently, offering the potential for recovery of sediment communities between events. These events loosen sediment, making it more susceptible to erosion and further stimulating damaging scour impacts (Yeo \& Risk 1979). While sediment grain size can mediate the effect of disturbance on communities (Lindegarth \& Hoskin 2001), grain size itself can also become altered by intense disturbance effects (Bishop 2005) thereby facilitating a change in community structure.

The aim of this study was to explore how the stressors, nutrient enrichment and physical disturbance, interact under natural field conditions. Nutrient enrichment and physical disturbances often overlap in time and space. For example, nutrient enrichment influences whole catchments, within which physical disturbances may also occur at smaller scales. Additionally, storm events that flush nutrient pollution into estuarine and coastal areas may also cause physical disturbance (Harris 2014). Despite this, most studies that have examined effects of these stressors on sediment communities have done so independently, and those that have examined interacting effects have done so in small-scale mesocosm experiments (see Widdicombe \& Austen 2001, Austen \& Widdicombe 2006). According to Huston's (1979) dynamic equilibrium model, that posits that larger disturbances will be required to disrupt competitive dominance when productivity is high, the two stressors are predicted to display non-additive effects. Mesocosm experiments provide support for this hypothesis (Widdicombe \& Austen 2001, Austen \& Widdicombe 2006). In buckets, experimental manipulations of nutrient enrichment (via addition 
of dried and powdered Ascophyllum) and physical disturbance (via surface raking) revealed that diversity was lower than expected when low frequencies of physical disturbance were applied in combination with high levels of organic enrichment or vice versa (Widdicombe \& Austen 2001, Austen \& Widdicombe 2006). Diversity was higher than expected when both disturbance and enrichment were either high or low (Widdicombe \& Austen 2001). Despite these results, it is unknown whether these non-additive effects also occur in field systems in which environmental conditions may buffer effects and recruitment of fauna is possible. Here, manipulative field experiments were conducted in two estuaries of eastern Australia to test the hypotheses that (1) the two stressors would display non-additive effects on microphytobenthic and macrofaunal communities, that are not easily predicted from their independent effects and (2) the nature of interactions would vary across field sites that differ in biotic and abiotic conditions.

\section{Materials and Methods}

\section{Study site}

Field experiments were conducted between May and September 2012 at two locations within Sydney, New South Wales, Australia: Tambourine Bay within Lane Cove River (3349'39"S $\left.151^{\circ} 09^{\prime} 38^{\prime \prime E}\right) ;$ and Woolooware Bay within Botany Bay (34 $\left.01^{\prime} 11^{\prime \prime} \mathrm{S}, 151^{\circ} 07^{\prime} 46^{\prime \prime E}\right)$. Sites were unvegetated intertidal mud flats, adjacent to mangrove habitat. Each was within $15 \mathrm{~km}$ of the estuary mouth, was situated in a highly urbanised catchment, and had sandy-mud sediments. Sites were away from storm-water drains, which transport nutrients into estuaries. Although the sites may be subject to some, minimal, trampling and the occasional boat run-aground, neither was subject to background raking or substantial bait-digging prior to experimental intervention. 
At an intertidal elevation of $\sim 0.5 \mathrm{~m}$ above mean low water springs, 70 square plots $(0.5 \times 0.5 \mathrm{~m}$ in size) were randomly established, and marked by a single post in the upper left corner of the plot. Each plot was separated by approximately 3 metres.

\section{Experimental approaches}

128 The interactive effect of stressors was determined using a fully orthogonal experimental design with two factors, nutrient enrichment and physical disturbance. Each factor had three levels of disturbance intensity: zero, low or high. Seven plots were randomly assigned to each of the resulting nine experimental treatments. The remaining seven plots were procedural controls for the method of nutrient enrichment (see below).

Physical disturbance was manipulated by raking sediments (50 cm wide rake) to a depth of 2-4 cm. Raking is one of the most commonly used methods for physically disturbing sediments (e.g. Cowie et al. 2000, Whomersley et al. 2010), and mimics cockle hand raking (Kaiser et al. 2001, Mistri et al. 2004). For plots assigned to the low or high physical disturbance, an area of approximately $1 \mathrm{~m}^{2}$, centring on but extending beyond the experimental plot was raked in a cross-hatched pattern. The low treatment consisted of two strokes of the rake, perpendicular to one another. This level of disturbance has previously been shown to illicit a response from intertidal communities (Whomersley et al. 2010). The high treatment consisted of 6 strokes, each stroke perpendicular to the previous. This disturbance was applied at the start of experiment and then monthly, over a four-month period.

Nutrient plots were enriched using Scotts Osmocote Pro, 8-9 month coated fertiliser pellets (N:P:K ratio of 16:4.8:8.3). These pellets which gradually release nutrients provide a controlled method of 
testing the effects of chronic nutrient enrichment in soft sediment benthic environments without need for replenishment (Worm et al. 2000). Plots were given $0 \mathrm{~g}$ (zero), $500 \mathrm{~g}$ (low) or $1000 \mathrm{~g}$ (high) of fertiliser. The high nutrient treatment was based on the level of nutrient loading that might be experienced in the vicinity of the discharge point of a moderately sized sewage treatment plant (Morris \& Keough 2002, 2003a, O'Brien et al. 2010) and the low treatment was set at half of this. For each of the plots assigned to the high or low nutrient treatment, nutrients were dispensed via five bags per plot, made from nylon panty-hose, among which the fertiliser was evenly distributed. These bags were spread evenly within each plot and were buried approximately $2-4 \mathrm{~cm}$ below the surface of the sediment. The nylon provided a fine permeable membrane through which nutrients could leach out into the plots. A procedural control tested for any experimental artefacts associated with burying the fertiliser; for this treatment nylon bags contained sediment in place of fertiliser and were deployed in the same manner as the nutrient treatments. Nylon bags containing slow release fertiliser or sediment (for the procedural control) were added to plots at the start of the experiment.

\section{Sampling}

Prior to initial manipulation of stressors, the chlorophyll and organic content of a subset $(n=25)$ of plots was sampled to determine background conditions at each site. Additionally, the spectral reflectance of the sediment and the macrofaunal community were sampled in each plot immediately prior to the manipulation of stressors. All variables were subsequently sampled monthly, for four months, in the case of sediment properties and at 2 (July) and 4 (September) months for macrofauna. Sampling of chlorophyll $a$ content and spectral reflectance were together 
used as proxies for the biomass of microphytobenthos (Tolhurst et al. 2005, Kromkamp et al.

2006). Sampling was conducted immediately prior to each re-application of the physical

disturbance treatment. Sampling at Lane Cove was not possible in the first month following initial disturbance due to large amounts of overlying water caused by a sizable low pressure system. The location of sample collection within each plot at each sampling time was noted, so as to avoid repeated collection of samples from the same area.

The sediment organic content and chlorophyll $a$ concentration was assessed through the contact coring method (Ford \& Honeywill 2002) whereby the top $2 \mathrm{~mm}$ of the sediment surface was flashfrozen with liquid nitrogen and then freeze dried. A single randomly-positioned $2463 \mathrm{~mm}^{2}$ core was collected from each plot at each sampling time. Over a period of 48 hours, photosynthetic pigments were extracted from a $200 \mathrm{mg}$ subsample of sediment from each core using $1.5 \mathrm{ml}$ of $90 \%$ acetone under dark conditions within a $-80{ }^{\circ} \mathrm{C}$ freezer. Samples were agitated after 24 hours for 10 seconds by using a vortex mixer. The chlorophyll $a$ concentration of the acetone solution was determined spectrophotometrically using the method of Jeffrey \& Humphrey (1975) and the chlorophyll $a$ content of sediment was calculated per unit area $\left(\mathrm{mg} \mathrm{m}^{-2}\right)$. A second $2 \mathrm{~g}$ subsample of sediment was taken from each contact core to determine the organic content through loss-onignition $\left(450^{\circ} \mathrm{C}\right.$ for 4 hours).

An Ocean Optics USB2000 spectroradiometer was used to measure the spectral reflectance of the sediment surface in situ. Reflectance values (R) were made in the visible $(675 \mathrm{~nm})$ and infra-red 
186 (NDVI), a measure of the photosynthetically-related biomass based upon reflectance of chlorophyll $a$ in the sediment (Kromkamp et al. 2006):

$N D V I=(R 750-R 675) /(R 750+R 675)$

Three measurements were collected per plot allowing an average NDVI to be calculated.

Reflectance measurements were discarded where there was interference from surface water.

Nevertheless, at each sampling time measurements from at least $n=3$ plots per treatment could be included in the analyses.

One large core (10 cm diameter, $10 \mathrm{~cm}$ depth) was collected from each plot to quantify macrofaunal biodiversity each of the sampling times indicated above. Sediment cores were taken from between nylon bags, so as not to disrupt dispense of nutrients. Sediment core samples were sieved through a $500 \mu \mathrm{m}$ diameter mesh and material retained on the sieve was fixed in $10 \%$ buffered formalin. Retained material was subsequently transferred into $70 \%$ ethanol and examined under a dissecting microscope to separate fauna from other remaining material. Fauna were identified to species level or morphospecies where this was not possible.

\section{Statistics}

Permutational analyses of variance (PERMANOVA: Anderson 2001, Anderson et al. 2008) were used to analyse univariate and multivariate data. Although initially developed for multivariate application, PERMANOVA can also be run on univariate data (Anderson et al. 2008) and has the advantage over ANOVA that it does not have assumptions regarding the underlying distribution of the data and can be used on any distance matrix (Anderson et al. 2008). Multivariate analyses, 
using Bray Curtis dissimilarities, were run on macrofaunal composition data. Macrofaunal

composition data was square-root transformed prior to PERMANOVA in order to down-weigh the effect of species dominance and ordinated using two-dimensional non-metric multidimensional scaling (nMDS). Univariate tests, using Euclidean distance matrices, were run on each of sediment organic content, chlorophyll a content, NDVI, Shannon's diversity of macrofauna, total abundance of macrofauna, species richness of macrofauna, as well as the abundance of macrofaunal species that were key discriminators of multivariate differences among treatments.

First, for macrofauna and NDVI variables, three-way analyses on time 0 data, collected prior to application of perturbations, and including the factors nutrient enrichment (fixed; 3 levels: zero $[O N]$, low $[L N]$, high [HN]), physical disturbance (fixed; 3 levels: zero [OD], low [LD], high [HD]) and site (fixed; 2 levels) tested for any pre-existing differences in variables of interest among plots and between sites that coincided with their treatment assignment. Due to only a subset of contact core samples taken in the first month we were unable to run a complete analysis testing differences between treatments for chlorophyll $a$ and organic content, however a one-way analysis was conducted testing for differences between sites. Second, four-way analyses, with the factors time (4 levels for most variables [1, 2, 3, 4 months after perturbation], and 2 levels for macrofauna [2, 4 months]), site (2 levels, random), treatment (2 levels: undisturbed, disturbance control) and plot (random; nested within site and treatment) tested for experimental artefacts of the method of nutrient application. Third, five-factor analyses with the factors site (random, 2 levels); nutrient enrichment (fixed; 3 levels); physical disturbance (fixed; 3 levels); plot (random, 7 levels, nested within site $\mathrm{x}$ nutrients $\mathrm{x}$ disturbance) and time (random, 2 or 4 levels) tested for 
interacting effects of the two stressors across both sites and all time periods. The inclusion of plot as a nested factor enabled time to be treated as a repeated measure. Following these analyses pairwise post hoc tests were conducted to identify significant differences between factors. Where the number of possible permutations was lower than 100, Monte Carlo (MC) testing was run to generate $p$-values from constructed asymptotic permutation distributions for the pseudo- $F$ statistic. All analyses were conducted using the PRIMER v6 statistical program with the PERMANOVA+ addition (Clarke \& Gorley 2006, Anderson et al. 2008).

The macrofaunal multivariate analysis revealed large spatial and temporal differences in communities resulting in strong interactions between month and site. These prevented the factors of interest (nutrient enrichment and physical disturbance) from being appropriately tested and so separate tests were run for each month and site using a reduced model including only the factors nutrient enrichment and physical disturbance. Key discriminating species, contributing to multivariate differences in macrofaunal community structure, were identified by SIMPER analysis and were defined as those having a dissimilarity/standard deviation ratio $>1$ between nutrient or physical disturbance treatments. Of these, species that were present at both sites were analysed using the complete 5 -factor model, with abundances $4^{\text {th }}$ root transformed. Discriminating species that were unique to a site were analysed under the reduced 2-factor model. Permutational 244 multivariate dispersions (PERMDISP) were analysed alongside the multivariate PERMANOVAs to assess the extent to which any treatment effects were driven by differences in dispersion between treatments and unless otherwise indicated were non-significant. 


\section{Results}

\section{Microphytobenthic component}

Prior to experimental manipulations there were no differences in organic content or chlorophyll $a$ content of sediments between the two sites, although NDVI was significantly greater at Lane Cove than Botany Bay (main effect of site PERMANOVA: $p<0.05$; see supplemental materials). Across the two sites, there were no pre-existing differences in NDVI among plots that corresponded to treatment assignments (PERMANOVA p > 0.05, see supplemental materials; insufficient plots were sampled to address this question for organic content and chlorophyll $a$ ). At none of the sampling times following application of stressors were there experimental artefacts of the method of fertiliser burial on any of the three variables, organic content, chlorophyll $a$ or NDVI (PERMANOVA $\mathrm{p}>0.05$; see supplemental material).

Organic content did not respond to the addition of stressors at either site (Table 1).By contrast, site-specific effects of stressors on the two measures of MPB biomass, chlorophyll $a$ concentration and NDVI were observed (Table 1). Neither variable displayed interactive effects between the two stressors so additive effects could be interpreted. Chlorophyll $a$ concentration displayed a significant interaction between physical disturbance, site and month (Table 1; Figures $1 A, B)$, whereas there was no effect of physical disturbance on NDVI at either site (Table 1). In Botany Bay (Figure 1A), although a slight negative impact of high physical disturbance on chlorophyll $a$ was observed in August (month 3), prior to September (month 4) the effects of disturbance were non-significant (a posteriori pairwise comparisons $p>0.05 ; 0 D=L D=H D$ ). $\ln$ 
chlorophyll $a$ concentration than those not receiving physical disturbance $(t=1.99, p(p e r m)=$ 0.048). There were no differences between the undisturbed and low disturbance treatments $(\mathrm{t}=$ 1.59, $p($ perm $)=0.113)$, or the low and high disturbance treatments $(t=0.14, p($ perm $)=0.898)$. At Lane Cove (Figure 1B), lower levels of chlorophyll were observed in plots receiving high than low physical disturbance in July (month 2; $H D<L D, t=3.42, p($ perm $)=0.002)$, but in August these two treatments did not significantly differ, and there were no significant differences between other pairs of treatments in either July or August (a posteriori pairwise comparisons: $p>0.05$ ). In September, low disturbance resulted in significantly greater concentrations of chlorophyll $a$ than in the undisturbed $(t=2.34, p($ perm $)=0.022)$ or high disturbance treatment $(t=2.97, p($ perm $)=$ 0.004), but there was no difference between the high disturbance and undisturbed treatments ( $t$ $=0.71, p($ perm $)=0.497)(L D>0 D=H D)$.

Despite chlorophyll $a$ displaying a significant interaction between nutrient addition and month ( $\mathrm{N}$ x $\mathrm{M}$ interaction; Table 1) and a weak trend for a greater concentration of in plots receiving a low or high nutrient addition than no nutrients (Figure 1C, D), in none of the months were significant differences among nutrient treatments found (a posteriori pairwise comparisons: $p>0.05$ ). By contrast, NDVI displayed a significant interaction between nutrient enrichment and site (Table 1), with effects of nutrient enrichment apparent in Botany Bay only (Figure 2). In Botany Bay, plots receiving either a low $(t=2.16, p($ perm $)=0.032)$ or high nutrient addition $(t=2.75, p(p e r m)=$ 0.011 ) had a significantly greater NDVI than unenriched plots. There were no differences between the low and the high treatment $(t=0.63, p($ perm $)=0.557)(0 N<L N=H N)$. 


\section{Macrofauna}

Analysis of macrofaunal community structure prior to manipulations revealed that multivariate community composition differed significantly between the sites $\left(\right.$ Pseudo- $F_{(1,108)}=31.63, \mathrm{p}(\mathrm{perm})$ $=0.001)$, with a greater abundance of invertebrates per plot at Lane Cove than Botany Bay (Pseudo- $F_{(1,108)}=3.70, \mathrm{p}($ perm $\left.)=0.031\right)$. Sixty-five species were identified, of which 28 were common between the two sites, 19 species were unique to Botany Bay and 18 were unique to Lane Cove. Shannon Diversity and total plot species richness did not significantly differ between the two sites (PERMANOVA $p>0.05$; see supplemental materials). At neither of the sites were there pre-existing differences among plots that corresponded to treatment assignments (see supplemental materials). Furthermore, at none of the sampling times were there experimental artefact associated of the method of nutrient addition on macrofauna (PERMANOVA $p>0.05$; see supplemental materials).

In the analysis comparing stressor impacts to macrofauna between the two sites, and across all sampling times, there was no effects of nutrient enrichment or physical disturbance on community composition or biodiversity indices, however there was a significant interaction between month and site (PERMANOVA: $p($ perm $)<0.05)$. When sites and times were considered separately, stressor effects on macrofauna could not be distinguished in July (PERMANOVA, $p$ > 0.05) and in September, following four months of continued exposure to stressors, there was no interacting effect of nutrients and physical disturbance on any of the measures of macrofaunal community structure, at either site, allowing interpretation of main effects (Table 2). Whereas the September analysis revealed no effect of physical disturbance on any of the measures of 
macrofaunal community structure, nutrient enrichment affected multivariate community composition at Botany Bay and at Lane Cove it had a weak, though non-significant effect on this variable (Table 2; Figure 3). At Botany Bay, the highly enriched treatment was significantly different to the unenriched treatment only $(t=1.63, p($ perm $)=0.031)$, with no differences between the low and the highly enriched treatments $(t=1.36, p($ perm $)=0.077)$ or between the low enrichment and unenriched treatments $(t=1.04, p($ perm $)=0.386)$. Additionally at Botany Bay the multivariate dispersions were significantly greater in the enriched plots in comparison to the controls (PERMANOVA, a posteriori tests, ON $<$ LN $=$ HN; PERMDISP: $F_{(2,58)}=8.94$, p $($ perm $)=$

0.002). There were no treatment effects on Shannon diversity for either Botany Bay or Lane Cove (Table 2). However, for Lane Cove, there was a treatment effect of nutrient enrichment on the total macrofaunal abundance whereby increasing enrichment caused a decrease in total abundance (Table 2; PERMANOVA, a posteriori tests, $\mathrm{ON}>\mathrm{LN}>\mathrm{HN}$ ). Analysis of dispersions also revealed increased nutrient enrichment significantly decreased the dispersion of abundances at Lane Cove with no differences in dispersion of either low or highly enriched treatment (ON > LN, HN; PERMDISP: $F_{(2,58)}=7.06, \mathrm{p}($ perm $\left.)=0.027\right)$.

SIMPER analysis identified six discriminating species contributing most to dissimilarity between nutrient treatments in Botany Bay, four of which coincided with those found in Lane Cove. These were Mysella sp., Mediomastus australiensis, Prionospio sp., and Nephtys australiensis. These species were among the most abundant species found at each site. The additional discriminating species at Botany Bay were Salinator fragilis and Owenia australis. Lane Cove had a total of 12 discriminating species which also included two species of Gammarus amphipods, Oedicerotidae 
sp. amphipods, Scoloplos sp., Laternula sp., Platynereis uniseris, Australonereis ehlersi and large nematodes.

In repeated measures analyses that included both sites, $M$. australiensis did not display any significant effects of nutrient enrichment or physical disturbance at either of the sites or at any of the sampling times (Table 3). Nutrient enrichment caused a significant alteration of the abundance of Prionospio sp. at Botany Bay only (nutrient enrichment x site interaction; Table 3; $a$ posteriori pairwise comparisons: $\mathrm{p}<0.05$; Figure 4). Pairwise comparisons revealed that at Botany Bay, the high nutrient enrichment plots had significantly lower Prionospio sp. abundances than the unenriched plots $(t=2.42, p($ perm $)=0.016)$ whereas there were no significant differences between the unenriched and low enrichment plots, or the low and high enrichment plots $(p>$ 0.05).

Across both sites and all sampling times, there was a significant interaction between nutrient enrichment and physical disturbance for the species N. australiensis (Table 3; Figure 4). There were no significant differences due to the impact of disturbance among plots that received either zero or high enrichment (a posteriori pairwise comparisons: $p>0.05$ ). Among plots that received low nutrient enrichment, abundances of $N$. australiensis were significantly greater in plots that also received low physical disturbance than those that were not disturbed (LD $>0 D ; t=16.64$, $p($ perm $)=0.013)$, with no significant difference between plots receiving high or low physical disturbance $(t=0.40, p($ perm $)=0.829)$ and between plots receiving high or no physical disturbance $(t=1.94, p($ perm $)=0.223)$. By contrast, among plots receiving high or zero nutrient enrichment, there was no significant effect of physical disturbance on $N$. australiensis abundance 
(a posteriori pairwise comparisons: $p>0.05$ ). When the interaction was examined around the other way around, there was no significant effect of nutrient enrichment, within any of the three levels of physical disturbance (a posteriori pairwise comparisons: $p>0.05$ ).

Mysella sp. displayed a three-way interaction between nutrient enrichment, physical disturbance and month, with no differences between sites (Table 3; Figure 4). Among unenriched plots, there was no significant effect of physical disturbance in either of the months (a posteriori pairwise comparisons: $p>0.05)$. Among plots subjected to low nutrient enrichment, abundances were greater in plots receiving high than no physical disturbance in each of the months (HD > OD; July: $t$ $=21.30, p(M C)=0.037 ;$ September: $t=19.32, p(M C)=0.031)$ and in July, there was also a significant difference between the high and low disturbance treatment $(H D>L D ; t=22.42, p(M C)$ $=0.037)$ but all other pairwise comparisons were non-significant $(p>0.05)$. Among plots receiving high nutrient enrichment, plots receiving high physical disturbance had greater abundances of Mysella sp. than undisturbed plots in July $(H D>0 D ; t=31.87, p(M C)=0.017)$, whereas in September, highly disturbed plots contained fewer individuals than those that were undisturbed $(H D<0 D ; t=12.33, p(M C)=0.049)$, with no other pairwise comparisons between levels of physical disturbance significant for either of the sampling times $(p>0.05)$. Examining the interaction around the other way, in July, plots receiving no physical disturbance had lower abundances of Mysella sp. when they received low as compared to no nutrient enrichment(ON > $L N ; t=51.61, p(M C)=0.013)$, but other pairwise contrasts revealed no other significant differences (a posteriori pairwise comparisons: $p>0.05$ ). In September, both the low and high nutrient treatments had lower abundances of Mysella sp. in comparison to the unenriched 
treatment (low: $\mathrm{t}=17.51, \mathrm{p}(\mathrm{MC})=0.33$; high: $\mathrm{t}=41.83, \mathrm{p}(\mathrm{MC})=0.017)$ but did not significantly differ from one another $(\mathrm{ON}>\mathrm{LN}=\mathrm{HN} ; \mathrm{t}=0.04, \mathrm{p}(\mathrm{MC})=0.977)$. There was no effect of nutrient enrichment on Mysella sp. among plots receiving low or high physical disturbance (a posteriori pairwise comparisons: $p>0.05)$.

Few of the species that were key discriminating taxa at only one of the two sites displayed significant responses to stressors (see supplemental materials: Table S4). At Lane Cove, Scoloplos sp. displayed a significant interaction between nutrient enrichment and physical disturbance $\left(\right.$ Pseudo- $F_{(2,52)}=2.91, p($ perm $)=0.039 ;$ Figure $\left.5 \mathrm{~A}\right)$. Among plots subjected to zero physical disturbance, plots receiving low $(t=2.23, p($ perm $)=0.034)$ and high $(t=2.13, p($ perm $)=0.050)$ nutrient contained fewer Scoloplos sp. than those receiving zero enrichment, with no differences between the low and high nutrient treatments $(0 N>L N=H N)$. By contrast, among plots receiving low or high physical disturbance, there was no effect of nutrient enrichment (PERMANOVA a posteriori tests: $p>0.05$ ). When the interaction was examined around the other way, among plots subjected to zero nutrient enrichment, high physical disturbance resulted in significantly fewer Scoloplos sp. as compared to undisturbed controls (OD $>\mathrm{HD} ; \mathrm{t}=2.46, \mathrm{p}($ perm $)=0.030$ ) whereas there were no differences between plots receiving low and no disturbance $(t=2.38, p(p e r m)=$ $0.064)$ or low and high disturbance $(t=0.12, p($ perm $)=0.99)$. Among plots receiving low or high nutrient enrichment, there was no significant effect of disturbance on Scoloplos sp. (PERMANOVA a posteriori tests: $p>0.05)$. At Lane Cove, nematodes displayed a significant main effect of nutrient enrichment only (Pseudo- $F_{(2,52)}=3.25, p($ perm $)=0.045$; Figure $5 B$ ) whereby abundance 
decreased with increasing nutrient enrichment $(\mathrm{ON}>\mathrm{LN}>\mathrm{HN}$; PERMANOVA a posteriori tests: $\mathrm{p}<$ 0.05).

\section{Discussion}

395

The limited number of mesocosm studies focussing on the interaction between physical disturbance and nutrient enrichment have highlighted the potential for interactions between these two stressors (Widdicombe \& Austen 2001, Austen \& Widdicombe 2006). This study sought to expand upon this earlier work by examining the interaction between nutrient enrichment and physical disturbance, under larger-scale field conditions that offer an element of ecological realism To our knowledge, it represented the first field-based study to examine the multiple effects of these two stressors in an intertidal sedimentary habitat (but see Rossi \& Underwood 2002 for a discussion on the impacts of organic matter burial that result both from physical disturbance of sediments and nutrient enrichment during decay). It found site-specific effects of nutrient enrichment and physical disturbance, with limited interactions between stressors. The study thereby demonstrates the role environmental context plays on mediating the impact of multiple stressors, and raises the possibility that communities may be more resilient to increased stress than can be predicted from laboratory studies alone.

Of the two stressors examined by this study, nutrient enrichment generally elicited stronger ecological responses than physical disturbance. Eastern Australian estuaries are, in general, oligotrophic and phosphorus-limited (Bishop et al. 2006, Scanes et al. 2007, Kelaher et al. 2013). In nutrient-limited systems such as these, nutrient enrichment typically stimulates bottom-up responses of the MPB (O'Brien et al. 2010, Pascal et al. 2013). This growth may then lead to 
cascading positive effects on higher trophic levels (York et al. 2012). Nevertheless, because excess primary production can also result in deterioration of sediment conditions through overstimulation of oxygen-consuming bacteria, the effects of nutrient enrichment on macrofaunal abundance and richness can range from positive (Morris \& Keough 2003a, b) to negative (Fitch \& Crowe 2010, Botter-Carvalho et al. 2014), depending on the level of enrichment and environmental conditions (Pearson \& Rosenberg 1978).

In the present study, an effect of nutrient enrichment on MPB was identified at both study sites (although effects were stronger in Botany Bay), and the effect was positive, in agreement with mesocosm studies (e.g. Sundback et al. 2010). While nutrient additions acted to alter macrofaunal community structure at each of the sites, effects were weaker than expected, with few species significantly affected by stressors, and the nature of effects variable between these. It has been hypothesised that estuarine communities have an inherent ability to resist stress at levels that would push other aquatic systems over a threshold, and which are above and beyond that which they are subjected to daily (e.g. salinity fluctuations, tides, and emersion periods; see Elliott \& Whitfield 2011). Within nature, biotic interactions may reduce the impacts of nutrient enrichment. The limited effects of nutrient enrichment observed in this study indicate there could be a mix of top down and bottom up effects impacting the community. Although in nutrientlimited systems, nutrient enrichment facilitates autotrophic growth, this effect can become masked by top down processes where increased productivity is matched by increased grazing pressure (Pascal et al. 2013). Alternatively, the weak effects of nutrient enrichment observed in the present study may be a function of other abiotic and biotic characteristics of the sites, an 
aspect that would be controlled for in closed systems. Sedimentary grain size and starting community composition can play an important role in interpreting how communities will respond to stressors (Lindegarth \& Hoskin 2001, Rossi \& Underwood, 2002, Whomersley et al. 2010). The relatively weak effects of nutrient enrichment detected in this study are consistent with largerscale surveys that indicate that nutrient enrichment is potentially a weak driver of change in benthic community composition in comparison to environmental characteristics, such as grain size (Nicastro \& Bishop 2013). Alternatively, the weak effects of nutrient enrichment seen in this study may reflect the small scale of manipulations. Larger-scale disturbances alter system dynamics ultimately impacting recovery and community resilience (Ellis et al. 2000).

Both MPB and macrofauna displayed a limited to neutral response to physical disturbance despite predictions, based on previous field studies, of negative effects of this stressor from destruction of sediment structure, burrows and damage to softer-bodied species (Hall 1994, Brown \& Wilson 1997, Hall \& Harding 1997, Dernie et al. 2003, Rossi et al. 2007). Community or species-specific responses to physical disturbance have been previously noted to vary according to environmental context (Whomersley et al. 2010) and previous mesocosm experiments have found that, in line with predictions of the Dynamic Equilibrium Hypothesis (Huston 1979), the effects of physical disturbance vary across productivity gradients caused by nutrient enrichment (Widdicombe \& Austen 2001, Austen \& Widdicombe 2006). Consistent with the Dynamic Equilibrium Hypothesis, a number of macrofaunal species in this study displayed responses to physical disturbance that varied according to the prevailing levels of nutrient enrichment. Overall, however, the number of 
species exhibiting such a non-additive responses was few, and nutrient enrichment was the dominant stressor impacting community composition in these systems.

While small scale disturbances such as raking and trampling sediments have been shown to negatively impact sediment communities in other studies (Rossi et al 2007; Whomersley et al 2010), the spatial scale and frequency of raking may simply not have been great enough to elicit a strong response in the communities examined here. In this experiment, plots were less than $1 \mathrm{~m}$ in diameter, allowing species to rapidly recolonise from outside affected areas (see Lee et al. 2011). This small scale of physical disturbance might be analogous to that caused by clam raking, by boat-run up on intertidal sediments or by propeller scaring. However, for disturbances, such as storms, that cause physical disturbance at the scale of the entire site, movement of species between affected areas would not be possible. Treatment effects at this level are likely to facilitate the selection for more resilient organisms that are able to tolerate stressors (Sanford \& Kelly 2011). The relatively (low) monthly frequency of raking may also have contributed to the weak to absent responses of taxa to physical disturbance. The frequency of disturbance is an important factor determining the magnitude of impact (Connell 1978, White \& Pickett 1985), with infrequent disturbances providing opportunity for organisms to recolonise in between, particularly if the spatial scale of the disturbance is small, but frequent disturbances preventing recovery before the next perturbation. Nevertheless, in Northern Europe, a single raking event covering an area of $36 \mathrm{~m}^{2}$, that perturbed large benthic species, had ecological impacts that extended a year (Kaiser et al. 2001). Impacts are, therefore, likely to be dependent on the size and scale of the raking event, as well as the species present. Although the physical disturbance 
475 imposed by repeatedly sampling of sediments may have complicated results by leading to small 476 scale disturbance across all experimental plots, irrespective of disturbance treatment (Lindegarth 477 and Underwood 2000), we were careful to sample different areas on each sampling date.

Within the literature, there are many examples of context dependent effects of manipulations, even across geographically proximate and/or environmentally similar locations (e.g Whomersley et al. 2010, Bishop \& Kelaher 2013, Gladstone-Gallagher et al. 2014). In this study, the differing response between the two sites to environmental perturbations may be a direct effect of environmental differences between sites, or an indirect effect arising from differences in their community composition. Although the two sites did not differ in background sediment organic content or chlorophyll concentration and were selected to be of similar grain size, other environmental variables are likely to have differed. Botany Bay is a large industrial area with a history of contamination whereas Lane Cove is surrounded by bushland and is used for recreational purposes such as bushwalking, boating and fishing. Habitat characteristics such as grain size, organic content and water content mediate the speed of benthic recovery from perturbations (Dernie et al. 2003). Additionally, under natural conditions, habitat heterogeneity can buffer against treatment effects (Godbold et al. 2011) or lead to substantial background variation, against which treatment effects are hard to detect (Bulling et al. 2008). Community

492 structure may mediate stressor impacts by dictating the functional capability of the ecosystem, and the ways in which species may interact to buffer the effects of stressors (Bulling et al. 2008,

494 Godbold \& Solan, 2009). 
Additionally, differences between the sites in background stressors may have contributed to the differing sensitivity of their communities to the experimental perturbations. Background stress can mediate how a system will respond to further stress via two main mechanisms. First, prevailing stress may select for organisms that have enhanced resistance to local stressors and so are able to withstand further disturbance (Sanford \& Kelly, 2011). Second, prevailing stressors can determine how far away a system is from a tipping-point beyond which the application of additional stress pushes the system over a threshold value, resulting in a system collapse (Pearson \& Rosenberg, 1978; Whomersley et al., 2010). How far away systems are from tipping points is related to the conditions to which fauna are adapted and the trade-offs they have made either through evolutionary or local adaptations (Sanford \& Kelly 2011, Botero et al. 2015). In dynamic environments subjected to multiple stressors such as estuaries, it would be expected that communities are dominated by species that are resilient to perturbation (Sanford \& Kelly 2011). Only where stressors exceed the threshold of resilience is there system collapse or change to another stable state.

Although previous mesocosm studies have identified interactions between nutrient enrichment and physical disturbance (e.g. Widdicombe \& Austen 2001), our study demonstrates that the results of such studies cannot necessarily be used to infer responses of benthic communities to stressors in the field. While some studies have found agreement between the outcomes of field and mesocosm experiments (e.g. Sundback et al. 2010), mesocosm studies can never completely replicate the natural environment and conclusions about the way in which multiple stressors interact can differ between these approaches (Przelawski et al. 2005; Crain et al. 2008, Alsterberg 
et al. 2014). For example, Cowie et al (2000) observed a negative effect of physical disturbance on the macrofauna in both experimental mesocosms and in situ treatments; however, the strength of the decline of species was greater in mesocosm experiments. Adverse effects are likely to be amplified in mesocosm studies due to the stress imposed on organisms as a consequence of handling and containment in confined conditions, and because processes such as recruitment that act to weaken impacts in field scenarios cannot always occur (see Cowie et al. 2000). The heterogeneity of environments such as mudflats and the patchiness of species can contribute to the differing responses observed between laboratory and mesocosm studies (Crain et al. 2008), or even between different field sites (Norkko et al. 2010). While mesocosms provide a controlled environment, there is a growing evidence that environmental context (such as prevailing nutrient status) are often the determinant factors governing how systems will respond to stress (Sundback 2007; Bishop \& Kelaher 2013; O'Connor \& Donohue, 2013). Thus it follows that while mesocosm and laboratory experiments are often a quick and simple tool in understanding the consequences of change, these experiments should be utilised to formulate theories to be tested empirically (see Benton et al. 2007), field experiments must be used to determine true impacts of stressors under naturally occurring conditions. Furthermore, the implications of multiple stressor impacts are well known to vary depending upon the experimental protocol (laboratory/mesocosm; see Crain et al. 2008 and references therein) or the responses measured (Alsterberg et al. 2014). The differing method of nutrient enrichment between our study, which applied fertiliser to plots, and the previous mesocosm studies that enriched sediments via application of dried and ground-up Ascophyllum (Widdicombe \& Austen 2001, Austen \& Widdicombe 2006), may have contributed to differences in the conclusions of these. Similarly, the differing frequency of physical disturbance 
between our study, which raked plots monthly, and the mesocosm experiments, that raked plots daily to monthly (Widdicombe \& Austen 2001, Austen \& Widdicombe 2006) may also have led to differences.

\section{Conclusions}

This study analysed the combined impact of selected multiple stressors -nutrient enrichment and physical disturbance - in a field setting. While both stressors have been previously identified to be detrimental to communities, and in mesocosm experiments produce non-additive effects, the combined impacts observed in this study were weak, mainly additive (at least at the chosen levels of stress), and mediated by environmental context. The differing results of this in situ study to those of previous mesocosm experiments, and the site-specificity of effects, highlight the important role that abiotic and biotic features of the environment play in mediating stressor effects. Furthermore, the resilience of benthic communities will determine their response to multiple stressors. The minor responses observed within this study highlight that benthic sedimentary communities are more resilient to increased stress than previous studies would indicate. Studies are now needed that examine which aspects of the environment or community are most important in mediating stressor impacts.

\section{$554 \quad$ References} effects on an illuminated benthic system. Biol Lett 10:20140640 
Anderson M, Gorley RN, Clarke RK (2008) Permanova+ for Primer: Guide to Software and Statistical Methods.

Austen MC, Widdicombe S (2006) Comparison of the response of meio- and macrobenthos to disturbance and organic enrichment. J Exp Mar Bio Ecol 330:96-104

Benton TG, Solan M, Travis JMJ, Sait SM (2007) Microcosm experiments can inform global ecological problems. Trends Ecol Evol 22:516-521

Bijma J, Pörtner H-O, Yesson C, Rogers AD (2013) Climate change and the oceans-what does the future hold? Mar Pollut Bull 74:495-505

Bishop MJ (2005) Compensatory effects of boat wake and dredge spoil disposal on assemblages of macroinvertebrates. Estuaries 28:510-518

Bishop MJ, Kelaher BP, Smith MPL, York PH, Booth DJ (2006) Ratio-dependent response of a temperate Australian estuarine system to sustained nitrogen loading. Oecol 149:701-708

Bishop MJ, Kelaher BP (2013) Context-specific effects of the identity of detrital mixtures on invertebrate communities. Ecol Evol 3:3986-3999

Botero CA, Weissing FJ, Wright J, Rubenstein DR (2015) Evolutionary tipping points in the capacity to adapt to environmental change. Proc Natl Acad Sci USA 112:184-189

Botter-Carvalho ML, Carvalho PVVC, Valença APMC, Santos PJP (2014) Estuarine macrofauna responses to continuous in situ nutrient addition on a tropical mudflat. Mar Pollut Bull 83:214-23

Brown B, Wilson WH (1997) The role of commercial digging of mudflats as an agent for change of infaunal intertidal populations. J Exp Mar Bio Ecol 218:49-61

Bulling MT, Solan M, Dyson KE, Hernandez-Milian G, Luque P, Pierce GJ, Raffaelli D, Paterson DM, White PCL (2008) Species effects on ecosystem processes are modified by faunal responses to habitat composition. Oecologia 158:511-520

Christensen MR, Graham MD, Vinebrooke RD, Findlay DL, Paterson MJ, Turner M a. (2006) Multiple anthropogenic stressors cause ecological surprises in boreal lakes. Glob Chang Biol 12:2316-2322

Clarke K, Gorley R (2006) PRIMER v6: User Manual/Tutorial. PRIMER-E, Plymouth.

Cloern J (2001) Our evolving conceptual model of the coastal eutrophication problem. Mar Ecol Prog Ser 210:223-253 
Connell JH (1978) Diversity in Tropical Rain Forests and Coral Reefs High diversity of trees and corals is maintained. Science 199:1302-1310

Cowie PR, Widdicombe S, Austen MC (2000) Effects of physical disturbance on an estuarine intertidal community: field and mesocosm results compared. Mar Biol 136:485-495

Crain CM, Kroeker K, Halpern BS (2008) Interactive and cumulative effects of multiple human stressors in marine systems. Ecol Lett 11:1304-1315

Darling ES, Côté IM (2008) Quantifying the evidence for ecological synergies. Ecol Lett 11:12781286

Dayton PK (1971) Competition, disturbance and community organization: the provision and subsequentutilization of space in a rocky intertidal community. Ecol Monograph 41:351-389

Dernie KM, Kaiser MJ, Warwick RM (2003) Recovery rates of benthic communities following physical disturbance. J Anim Ecol 72:1043-1056

Elliott M, Whitfield AK (2011) Challenging paradigms in estuarine ecology and management. Estuar Coast Shelf Sci 94:306-314

Ellis JI, Norkko A, Thrush SF (2000) Broad-scale disturbance of intertidal and shallow sublittoral soft-sediment habitats; Effects on the benthic macrofauna. J Aquat Ecosyst Stress Recover 7:57-74

Fitch JE, Crowe TP (2010) Effective methods for assessing ecological quality in intertidal softsediment habitats. Mar Pollut Bull 60:1726-33

Ford RB, Honeywill C (2002) Grazing on intertidal microphytobenthos by macrofauna: is pheophorbide $a$ a useful marker? Mar Ecol Ser 229:33-42

Fraterrigo JM, Rusak JA. (2008) Disturbance-driven changes in the variability of ecological patterns and processes. Ecol Lett 11:756-770

Gladstone-Gallagher RV., Lundquist CJ, Pilditch CA. (2014) Response of temperate intertidal benthic assemblages to mangrove detrital inputs. J Exp Mar Bio Ecol 460:80-88

Godbold JA, Bulling MT, Solan M (2011) Habitat structure mediates biodiversity effects on ecosystem properties. Proc Biol Sci 278:2510-8

Godbold JA, Solan M (2009) Relative importance of biodiversity and the abiotic environment in mediating an ecosystem process. Mar Ecol Prog Ser 396:273-282 
Gray JS (1997) Marine biodiversity patterns, threats and conservation needs. Biodivers Conserv 6:153-175

Hall SJ (1994) Physical disturbance and marine benthic communities: life in unconsolidated sediments. Oceanogr Mar Biol An Annu Rev Vol 32:179-239

Hall SJ, Harding MJC (1997) Physical disturbance and marine benthic communities: The effects of mechanical harvesting of cockles on non-target benthic infauna. J Appl Ecol 34:497-517

Halpern BS, Walbridge S, Selkoe KA, Kappel C V, Micheli F, D’Agrosa C, Bruno JF, Casey KS, Ebert C, Fox HE, Fujita R, Heinemann D, Lenihan HS, Madin EMP, Perry MT, Selig ER, Spalding M, Steneck R, Watson R (2008) A Global Map of Human Impact on Marine Ecosystems. Science 319:948-952

Harris PT (2014) Shelf and deep-sea sedimentary environments and physical benthic disturbance regimes: A review and synthesis. Mar Geol 353:169-184

Hicks N, Bulling MT, Solan M, Raffaelli D, White PCL, Paterson DM (2011) Impact of biodiversityclimate futures on primary production and metabolism in a model benthic estuarine system. BMC Ecol 11:Article No.: 7

Huston M (1979) A general hypothesis of species diversity. Am Nat 113:81-101

Jeffrey SW, Humphrey GF (1975) New spectrophotometric equations for determining chlorophylls $a, b, c 1$ and $c 2$ in higher-plants, algae and natural phytoplankton. Biochem Und Physiol Der Pflanz 167:191-194

Jones KMM, Boulding EG (1999) State-dependent habitat selection by an intertidal snail: the costs of selecting a physically stressful microhabitat. J Exp Mar Bio Ecol 242:149-177

Kaiser MJ, Broad G, Hall SJ (2001) Disturbance of intertidal soft-sediment benthic communities by cockle hand raking. J Sea Res 45:119-130

Kelaher BP, Van Den Broek J, York PH, Bishop MJ, Booth DJ (2013) Positive responses of a seagrass ecosystem to experimental nutrient enrichment. Mar Ecol Prog Ser 487:15-25

Kromkamp JC, Morris EP, Forster RM, Honeywill C, Hagerthey S, Paterson DM (2006) Relationship of intertidal surface sediment chlorophyll concentration to hyperspectral reflectance and chlorophyll fluorescence. Estuaries and Coasts 29:183-196

Lee KM, Lee SY, Connolly RM (2011) Short-term response of estuarine sandflat trophodynamics to pulse anthropogenic physical disturbance: Support for the Intermediate Disturbance Hypothesis. Estuar Coast Shelf Sci 92:639-648 
Lindegarth M, Hoskin M (2001) Patterns of distribution of macro-fauna in different types of estuarine, soft sediment habitats adjacent to urban and non-urban areas. Estuar Coast Shelf Sci 52:237-247

Lindegarth M, Underwood A (2002) A manipulative experiment to evaluate predicted changes in intertidal macro- faunal assemblages after contamination by heavy metals. J Exp Mar Biol Ecol 274:41-64

Menge BA, Sutherland JP (1987) Community regulation: Variation in disturbance, copetition, and predation in relation to environmental stress and recruitment. Am Nat:730-757

Mistri M, Cason E, Munari C, Rossi R (2004) Disturbance of a soft-sediment meiobenthic community by clam hand raking. Ital J Zool 71:131-133

Morris L, Keough MJ (2002) Organic pollution and its effects : a short-term transplant experiment to assess the ability of biological endpoints to detect change in a soft sediment environment. 225:109-121

Morris L, Keough MJ (2003a) Testing the effects of nutrient additions on mudflat macroinfaunal assemblages in the presence and absence of shorebird predators. Mar Freshw Res 54:859874

Morris L, Keough MJ (2003b) Variation in the response of intertidal infaunal invertebrates to nutrient additions: field manipulations at two sites within Port Phillip Bay, Australia. Mar Ecol Ser 250:35-49

Nicastro A, Bishop MJ (2013) Weak and habitat-dependent effects of nutrient pollution on macrofaunal communities of Southeast Australian estuaries. PLoS One 8:e65706

Nixon SW (1995) Coastal marine eutrophication - a definition, social causes, and future concerns. Ophelia 41:199-219

Norkko J, Norkko A, Thrush SF, Valanko S, Suurkuukka H (2010) Conditional responses to increasing scales of disturbance, and potential implications for threshold dynamics in softsediment communities. Mar Ecol Prog Ser 413:253-266

O'Brien AL, Morris L, Keough MJ (2010) Multiple sources of nutrients add to the complexities of predicting marine benthic community responses to enrichment. Mar Freshw Res 61:13881398

O'Connor N, Donohue I (2013) Environmental context determines multi-trophic effects of consumer species loss. Glob Change Biol 19:431-440 
680

Paine RT, Levin SA (1981) Intertidal landscapes : disturbance and the dynamics of pattern. Ecol Monogr 51:145-178

Pascal PY, Fleeger JW, Boschker HTS, Mitwally HM, Johnson DS (2013) Response of the benthic food web to short- and long-term nutrient enrichment in saltmarsh mudflats. Mar Ecol Prog Ser 474:27-41

Pearson TH, Rosenberg R (1978) Macrobenthic succession in relation to organic enrichment and pollution of the marine environment. Oceanogr Mar Biol Annu Rev 16:229-311

Przeslawski R, Byrne M, Mellin C. (2015) A review and meta-analysis of the effects of multiple abiotic stressors on marine embryos and larvae. Glob Change Biol 21:2122-2140

Rossi F, Forster RM, Montserrat F, Ponti M, Terlizzi a., Ysebaert T, Middelburg JJ (2007) Human trampling as short-term disturbance on intertidal mudflats: effects on macrofauna biodiversity and population dynamics of bivalves. Mar Biol 151:2077-2090

Rossi F, Underwood A (2002) Small-scale disturbance and increased nutrients as influences on intertidal macrobenthic assemblages: Experimental burial of wrack in different intertidal environments. Mar Ecol Prog Ser 241:29-39

Sanford E, Kelly MW (2011) Local adaptation in marine invertebrates. Ann Rev Mar Sci 3:509-35

Scanes P, Coade G, Doherty M, Hill R (2007) Evaluation of the utility of water quality based indicators of estuarine lagoon condition in NSW, Australia. Estuar Coast Shelf Sci 74:306-319

Somerfield PJ, Rees HL, Warwick RM (1995) Interrelationships in community structure between shallow-water marine meiofauna and macrofauna in relation to dredgings disposal. Mar Ecol Prog Ser 127:103-112

Sundback K, Alsterberg C, Larson F (2010) Effects of multiple stressors on marine shallow-water sediments: Response of microalgae and meiofauna to nutrient-toxicant exposure. J Exp Mar Bio Ecol 388:39-50

Sundback K, Peterson DG, Dahllöf I, Larson F (2007) Combined nutrient-toxicant effects on a shallow-water marine sediment system:sensitivity and resilience of ecosystem functions. Mar Ecol Prog Ser 330:13-30

Tolhurst TJ, Underwood AJ, Perkins RG, Chapman MG (2005) Content versus concentration: Effects of units on measuring the biogeochemical properties of soft sediments. Estuar Coast Shelf Sci 63:665-673 

35

Vitousek P, Aber JD, Howarth RW, Likens GE, Matson PA, Schindler DW, Schlesinger WH, Tilman GD (1997a) Human alteration of the global nitrogen cycle: Sources and consequences. Ecol Appl 7:737-750

Vitousek P, Mooney HA, Lubchenco J, Melillo JM (1997b) Human domination of Earth's ecosystems. Science 277:494-499

White PS, Pickett STA (1985). Natural disturbance and patch dynamics: an introduction. In Pickett STA, White PS (Eds.), The ecology of natural disturbance and patch dynamics. (pp. 3-13). Academic Press.

Whomersley P, Huxham M, Bolam S, Schratzberger M, Augley J, Ridland D (2010) Response of intertidal macrofauna to multiple disturbance types and intensities - an experimental approach. Mar Environ Res 69:297-308

Widdicombe S, Austen MC (2001) The interaction between physical disturbance and organic enrichment: An important element in structuring benthic communities. Limnol Oceanogr 46:1720-1733

Worm B, Reusch TBH, Lotze HK (2000) In situ nutrient enrichment: Methods for marine benthic ecology. Int Rev Hydrobiol 85:359-375

Wynberg RP, Branch GM (1994) Disturbance associated with bait-collection for sandprawns (Callianassa kraussi) and mudprawns (Upogebia africana): Long-term effects on the biota of intertidal sandflats. J Mar Res 52:523-558

Yeo RK, Risk MJ (1979) Intertidal catastrophes: effect of storms and hurricanes on intertidal benthos of the Minas Basin, Bay of Fundy. J Fish Res Board Canada 36:667-669

York P, Kelaher B, Booth D, Bishop M (2012) Trophic responses to nutrient enrichment in a temperate seagrass food chain. Mar Ecol Prog Ser 449:291-296 


\begin{tabular}{lrrrrrrrrr}
\hline & \multicolumn{3}{c}{ Organic content } & \multicolumn{4}{c}{ Chlorophyll $\boldsymbol{a}$} & \multicolumn{3}{c}{ NDVI } \\
\hline \multicolumn{1}{c}{ Factor } & Df & Pseudo- $\boldsymbol{F}$ & P(perm) & df & Pseudo- $\boldsymbol{F}$ & P(perm) & df & Pseudo- $\boldsymbol{F}$ & P(perm) \\
\hline N & 2 & 1.68 & 0.255 & 2 & 3.95 & 0.070 & 2 & 1.22 & 0.406 \\
D & 2 & 3.47 & 0.076 & 2 & 2.49 & 0.143 & 2 & 0.34 & 0.916 \\
M & 2 & 1.60 & 0.371 & 2 & 0.84 & 0.492 & 3 & 0.58 & 0.693 \\
S & 1 & $\mathbf{7 . 6 2}$ & $\mathbf{0 . 0 0 2}$ & 1 & 0.12 & 0.747 & 1 & 2.59 & 0.116 \\
NxD & 4 & 0.54 & 0.859 & 4 & 1.10 & 0.422 & 4 & 0.75 & 0.696 \\
NxM & 4 & 0.42 & 0.821 & 4 & $\mathbf{2 7 . 4 0}$ & $\mathbf{0 . 0 0 2}$ & 6 & 1.45 & 0.336 \\
NxS & 2 & 0.54 & 0.828 & 2 & 1.25 & 0.282 & 2 & $\mathbf{3 . 4 2}$ & $\mathbf{0 . 0 3 9}$ \\
DxM & 4 & 0.58 & 0.730 & 4 & 0.08 & 0.981 & 6 & 0.79 & 0.615 \\
DxS & 2 & 0.42 & 0.916 & 2 & 1.11 & 0.323 & 2 & 2.33 & 0.104 \\
MxS & 2 & 2.37 & 0.078 & 2 & $\mathbf{9 . 8 8}$ & $\mathbf{0 . 0 0 1}$ & 3 & $\mathbf{2 5 . 9 1}$ & $\mathbf{0 . 0 0 1}$ \\
NxDxM & 8 & 1.24 & 0.363 & 8 & 1.80 & 0.221 & 12 & 0.53 & 0.855 \\
NxDxS & 4 & 1.46 & 0.166 & 4 & 0.47 & 0.945 & 4 & 1.23 & 0.262 \\
NxMxS & 4 & 0.78 & 0.572 & 4 & 0.05 & 0.998 & 6 & 1.54 & 0.161 \\
DxMxS & 4 & 2.10 & 0.054 & 4 & $\mathbf{3 . 0 5}$ & $\mathbf{0 . 0 1 5}$ & 6 & 1.55 & 0.174 \\
P(NxDxS) & 107 & $\mathbf{1 . 8 3}$ & $\mathbf{0 . 0 0 2}$ & 112 & $\mathbf{1 . 5 6}$ & $\mathbf{0 . 0 0 5}$ & 110 & $\mathbf{1 . 9 3}$ & $\mathbf{0 . 0 0 1}$ \\
NxDxMxS & 8 & 1.30 & 0.230 & 8 & 0.83 & 0.577 & 12 & 1.69 & 0.083 \\
Res & 179 & & & 187 & & & 301 & & \\
\hline
\end{tabular}

Table 1: PERMANOVA analyses examining the interacting effects of Nutrients ( $N$ ), Disturbance (D), Month (M), and Site (S) on organic content, chlorophyll $a$ concentration and Normalised Difference Vegetation Index (NDVI) in Botany Bay and Lane Cove estuaries. Plot (P) was nested within NxDxS. Nutrient enrichment and physical disturbance factors contained 3 levels of applied stress (Zero, Low and High). The three months (2 - July, 3 - August, 4 - September) during which both sites were sampled are included in the analysis. $n=3-7$ for all treatments levels 
Table 2: Two-way PERMANOVA analyses examining the interacting effects of Nutrients $(\mathrm{N})$ and Disturbance (D) on the macrofaunal community at sites within Botany Bay and Lane Cove estuaries. Nutrient enrichment and physical disturbance factors contained 3 levels of applied stress (zero, low or high) over 4 months $(M) . n=5-7$ for all treatments levels

\begin{tabular}{|c|c|c|c|c|c|c|c|c|c|}
\hline & \multicolumn{3}{|c|}{ Species richness } & \multicolumn{2}{|c|}{ Abundance } & \multicolumn{2}{|c|}{ Shannon Diversity } & \multicolumn{2}{|c|}{ Multivariate } \\
\hline & df & Pseudo- $F$ & $p($ perm $)$ & Pseudo- $F$ & p(perm) & Pseudo- $F$ & $\mathrm{p}($ perm $)$ & Pseudo- $F$ & $p$ (perm) \\
\hline \multicolumn{10}{|c|}{ Botany Bay: } \\
\hline $\mathbf{N}$ & 2 & 0.67 & 0.562 & 0.51 & 0.618 & 1.20 & 0.311 & 1.92 & 0.035 \\
\hline D & 2 & 0.36 & 0.702 & 0.19 & 0.846 & 0.64 & 0.523 & 1.31 & 0.181 \\
\hline NXD & 4 & 0.48 & 0.767 & 0.52 & 0.766 & 0.55 & 0.699 & 0.98 & 0.476 \\
\hline Res & 52 & & & & & & & & \\
\hline \multicolumn{10}{|c|}{ Lane Cove: } \\
\hline $\mathbf{N}$ & 2 & 1.22 & 0.270 & 3.66 & 0.027 & 0.47 & 0.604 & 1.48 & 0.059 \\
\hline D & 2 & 0.34 & 0.727 & 0.70 & 0.493 & 0.59 & 0.548 & 0.68 & 0.882 \\
\hline NXD & 4 & 0.46 & 0.750 & 0.50 & 0.714 & 1.91 & 0.108 & 0.85 & 0.863 \\
\hline Res & 52 & & & & & & & & \\
\hline
\end{tabular}


Table 3: PERMANOVA analysis examining the interacting effects of Nutrients $(\mathrm{N})$, Disturbance (D), Month (M), and Site (S) on the key discriminating species common to both sites within Botany Bay and Lane Cove estuaries. Plot (P) was nested within NxDxS. Nutrient enrichment and physical disturbance factors contained 3 levels of applied stress (zero, low or high), with sampling after 2 and 4 months (i.e. July, September). $n=5-7$ for all treatment levels

\begin{tabular}{|c|c|c|c|c|c|c|c|c|c|}
\hline \multirow[b]{2}{*}{ Factor } & \multicolumn{3}{|c|}{$\begin{array}{c}\text { Mediomastus } \\
\text { australiensis }\end{array}$} & \multicolumn{2}{|c|}{ Prionospio sp. } & \multicolumn{2}{|c|}{$\begin{array}{c}\text { Nephtys } \\
\text { australiensis }\end{array}$} & \multicolumn{2}{|c|}{ Mysella sp. } \\
\hline & df & Pseudo-F & $\mathbf{P}($ perm $)$ & Pseudo- & $\mathrm{P}($ perm & Pseudo-F & $\mathbf{P}($ perm $)$ & Pseudo- & $\mathrm{P}($ perm \\
\hline $\mathbf{N}$ & 2 & 0.69 & 0.629 & 0.56 & 0.697 & 0.46 & 0.758 & 1.17 & 0.509 \\
\hline D & 2 & 0.78 & 0.586 & 0.66 & 0.631 & 1.62 & 0.324 & 0.17 & 0.949 \\
\hline M & 1 & 4.22 & 0.326 & 0.96 & 0.629 & 0.11 & 0.506 & 35.18 & 0.343 \\
\hline $\mathbf{S}$ & 1 & 13.98 & 0.001 & 2.90 & 0.086 & 14.03 & 0.001 & 7.15 & 0.010 \\
\hline$N x D$ & 4 & 0.21 & 0.977 & 1.87 & 0.197 & 4.66 & 0.026 & 2.87 & 0.087 \\
\hline NxM & 2 & 1.04 & 0.497 & 8.67 & 0.104 & 1.90 & 0.355 & 483.73 & 0.003 \\
\hline NxS & 2 & 0.68 & 0.530 & 2.64 & 0.045 & 2.13 & 0.138 & 1.15 & 0.310 \\
\hline DxM & 2 & 2.73 & 0.264 & 1.45 & 0.375 & 0.79 & 0.565 & 6.32 & 0.132 \\
\hline DxS & 2 & 0.80 & 0.466 & 1.11 & 0.397 & 0.48 & 0.637 & 0.69 & 0.512 \\
\hline MxS & 1 & 4.73 & 0.037 & 8.06 & 0.007 & 11.36 & 0.002 & 0.58 & 0.455 \\
\hline NxDxM & 4 & 4.22 & 0.092 & 0.92 & 0.516 & 0.27 & 0.893 & 6.81 & 0.045 \\
\hline NxDxS & 4 & 0.92 & 0.544 & 0.81 & 0.681 & 0.68 & 0.772 & 0.60 & 0.867 \\
\hline NxMxS & 2 & 1.69 & 0.193 & 0.25 & 0.769 & 0.20 & 0.833 & 0.01 & 0.989 \\
\hline DxMxS & 2 & 0.47 & 0.639 & 0.89 & 0.429 & 1.25 & 0.299 & 0.07 & 0.933 \\
\hline$P(N x D x S)$ & 11 & 1.46 & 0.033 & 1.12 & 0.295 & 0.97 & 0.570 & 3.08 & 0.001 \\
\hline NxDxMxS & 4 & 0.79 & 0.538 & 1.30 & 0.290 & 0.74 & 0.564 & 0.10 & 0.983 \\
\hline Res & 10 & & & & & & & & \\
\hline
\end{tabular}


Figure 1: Mean (+/- SE) chlorophyll $a$ concentration $\left(\mathrm{mg} \mathrm{m}^{-2}\right)$ of surface sediments in experimental plots. Differences among disturbance treatments through time at Botany Bay (A) and Lane Cove (B). Differences among nutrient treatments through time at Botany Bay (C) and Lane Cove (D). Sampling within Lane Cove could not be done in June due to large amounts of overlying water. For all graphs, 0 treatment $=$ circle, solid line; Low treatment $=$ square, long dashed line; High treatment = triangle; short dashed line. $n=3-7$ for all treatment levels.

Figure 2: Mean (+/- SE) normalised difference vegetation index (NDVI) at sites in Botany Bay (BB) and Lane Cove (LC) following 4 months of continued nutrient enrichment and physical disturbance crossed at 3 levels ( $0, \mathrm{~L}-$ Low, and $\mathrm{H}-\mathrm{High})$. Data averaged across all months and physical disturbance treatments as there was no month $\mathrm{x}$ nutrient or disturbance $\mathrm{x}$ nutrient enrichment interaction. $n=3-7$ for all treatment levels. Letters indicate statistically significant differences between treatments (PERMANOVA post hoc tests).

Figure 3: Two-dimensional nMDS configuration displaying macrofaunal composition at Botany Bay (A) and Lane Cove (B) following 4 months of zero (O) low (L) and high (H) nutrient enrichment 
(N) and physical disturbance (D). Points represent individual plots. Data square root transformed and matrix based upon Bray Curtis similarity. $\mathrm{N}=5-7$

Figure 4: Mean (+/-SE) abundance of common macrofaunal species in experimental plots at Botany Bay and Lane Cove following 4 months of nutrient enrichment and physical disturbance crossed at 3 levels ( $0, \mathrm{~L}-$ Low, and $\mathrm{H}-$ High) each. $\mathrm{N}=5-7$.

Figure 5: Mean (+/- SE) abundance of A) Scoloplos sp. and B) nematodes in experimental plots at Lane Cove following 4 months of nutrient enrichment and physical disturbance crossed at 3 levels (0, $\mathrm{L}-$ Low, and $\mathrm{H}-$ High) of each factor. $\mathrm{N}=5-7$ 


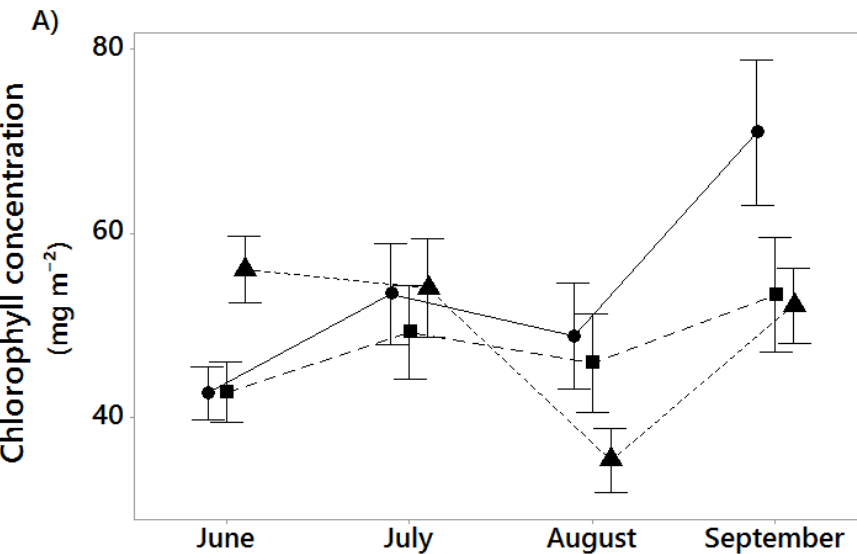

B)

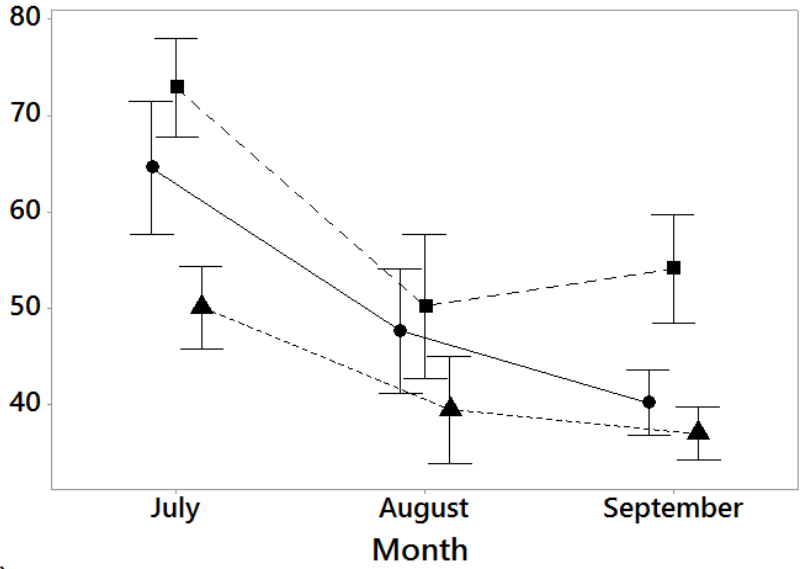

C)

D)
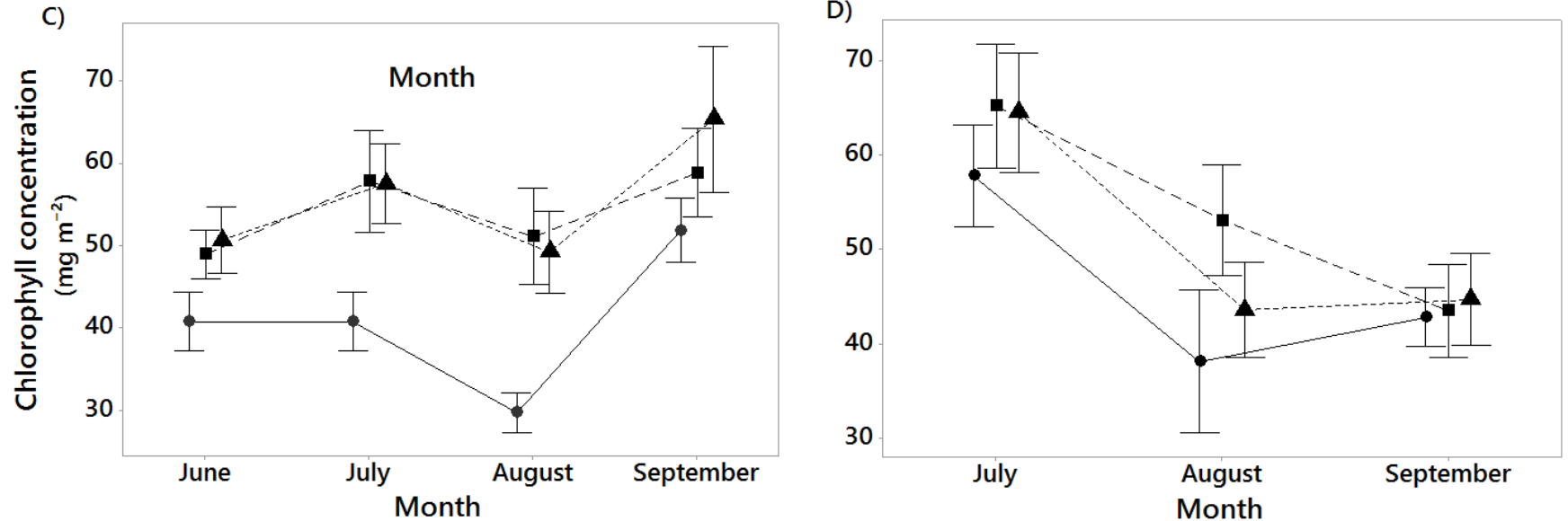

\section{Figure 1:}

791

792

793

794

795 


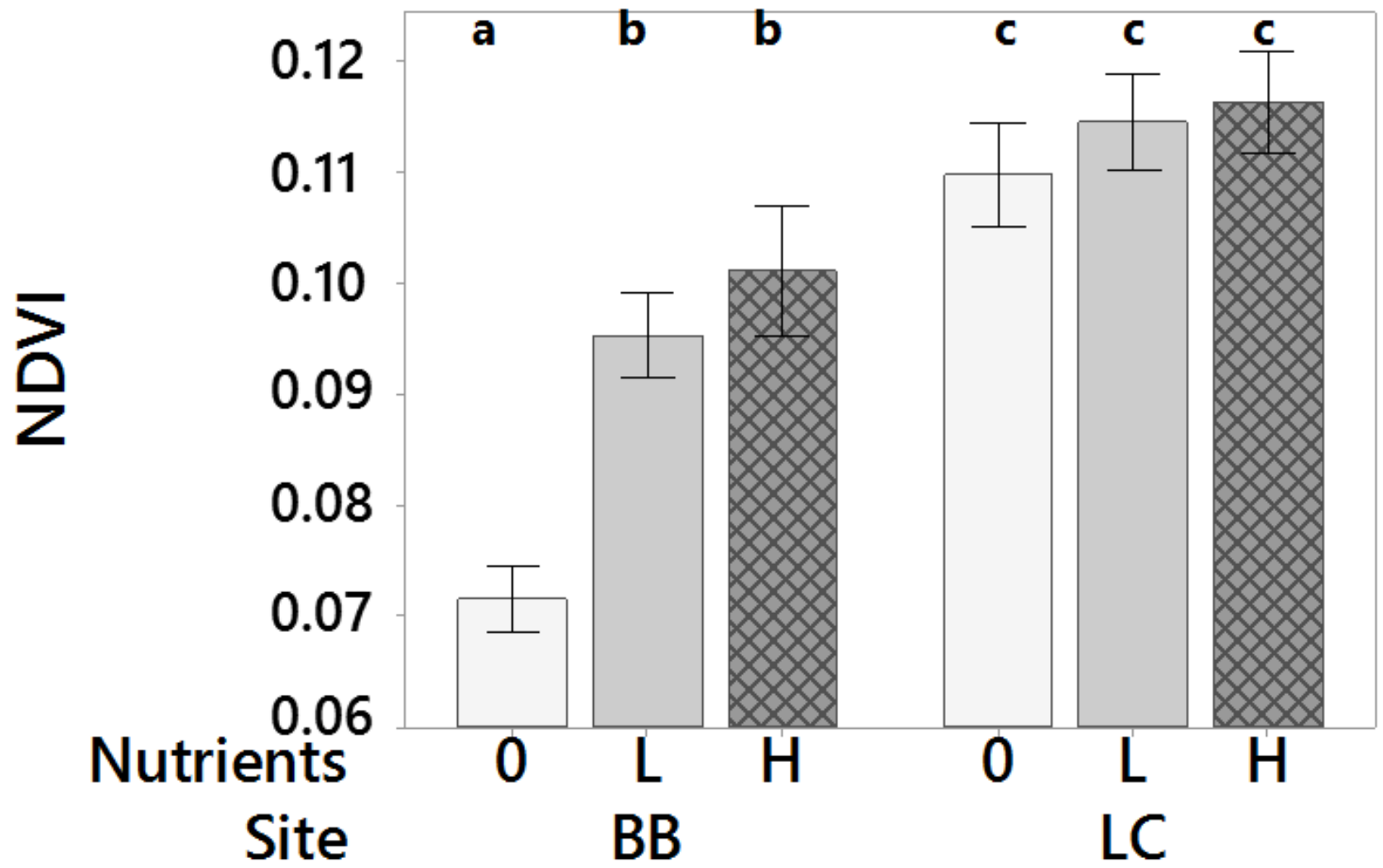

797 Figure 2: 


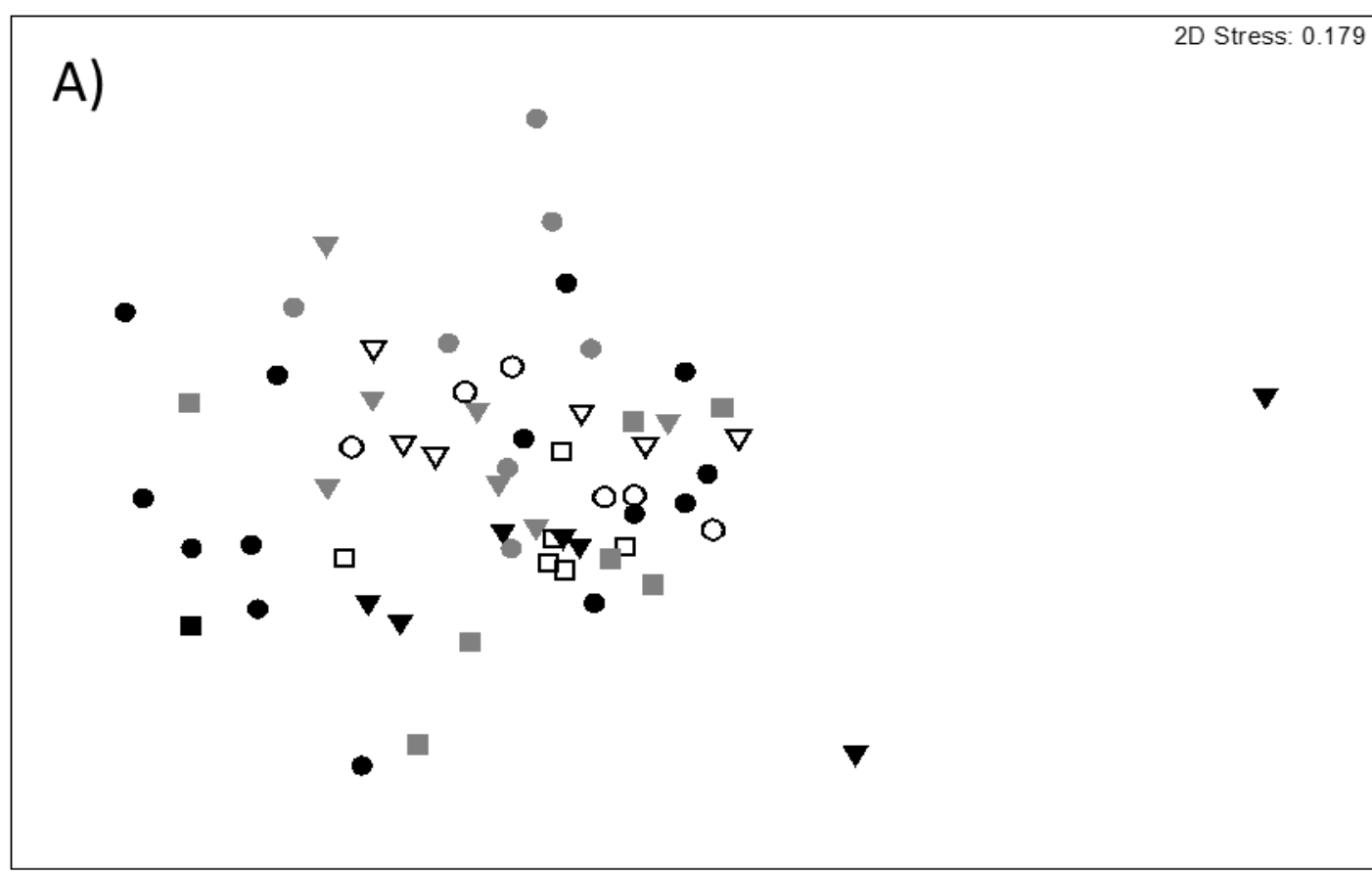

Treatment O ON OD $\nabla$ ON LD $\square$ ON HD - LN OD

- LN LD

- LN HD

- HN OD

$\checkmark \mathrm{HN}$ LD

- HN HD

B)

$\nabla$

2D Stress: 0.222

Treatment O ON OD $\nabla$ ON LD $\square$ ON HD - LN OD

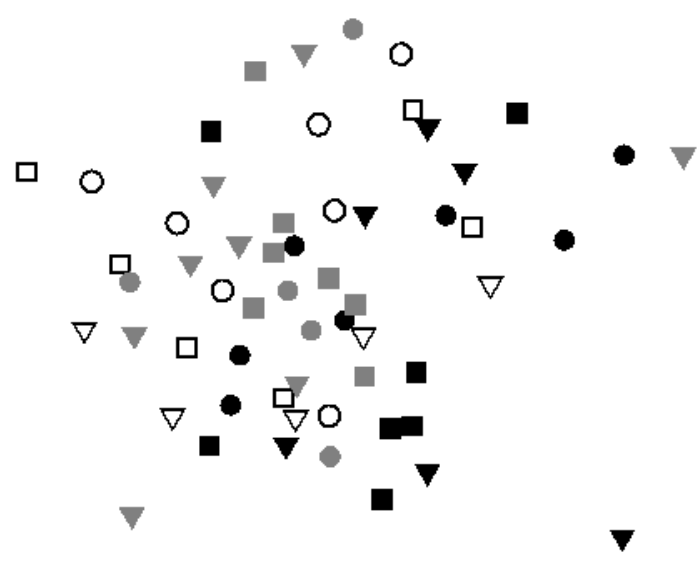
$\nabla$ LN LD - LN HD - HN OD $\checkmark$ HN LD

Figure 3: 
Botany Bay

Prionospio sp.

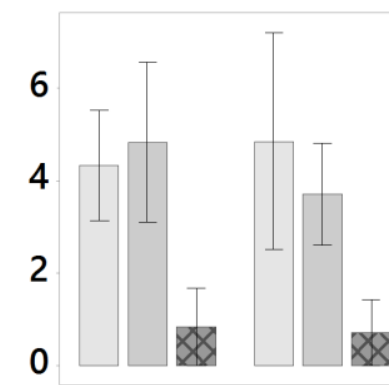

45

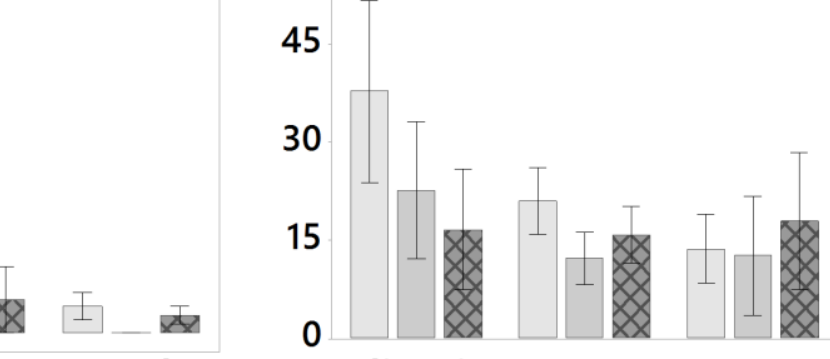

Nephtys australiensis

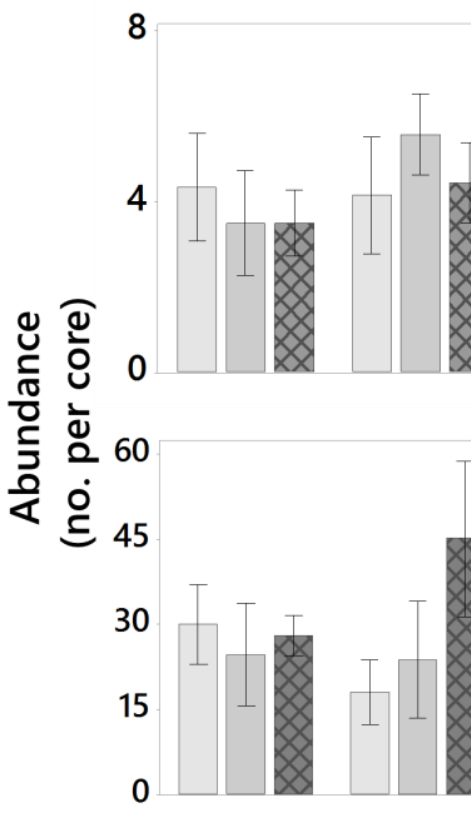

4

Lane Cove
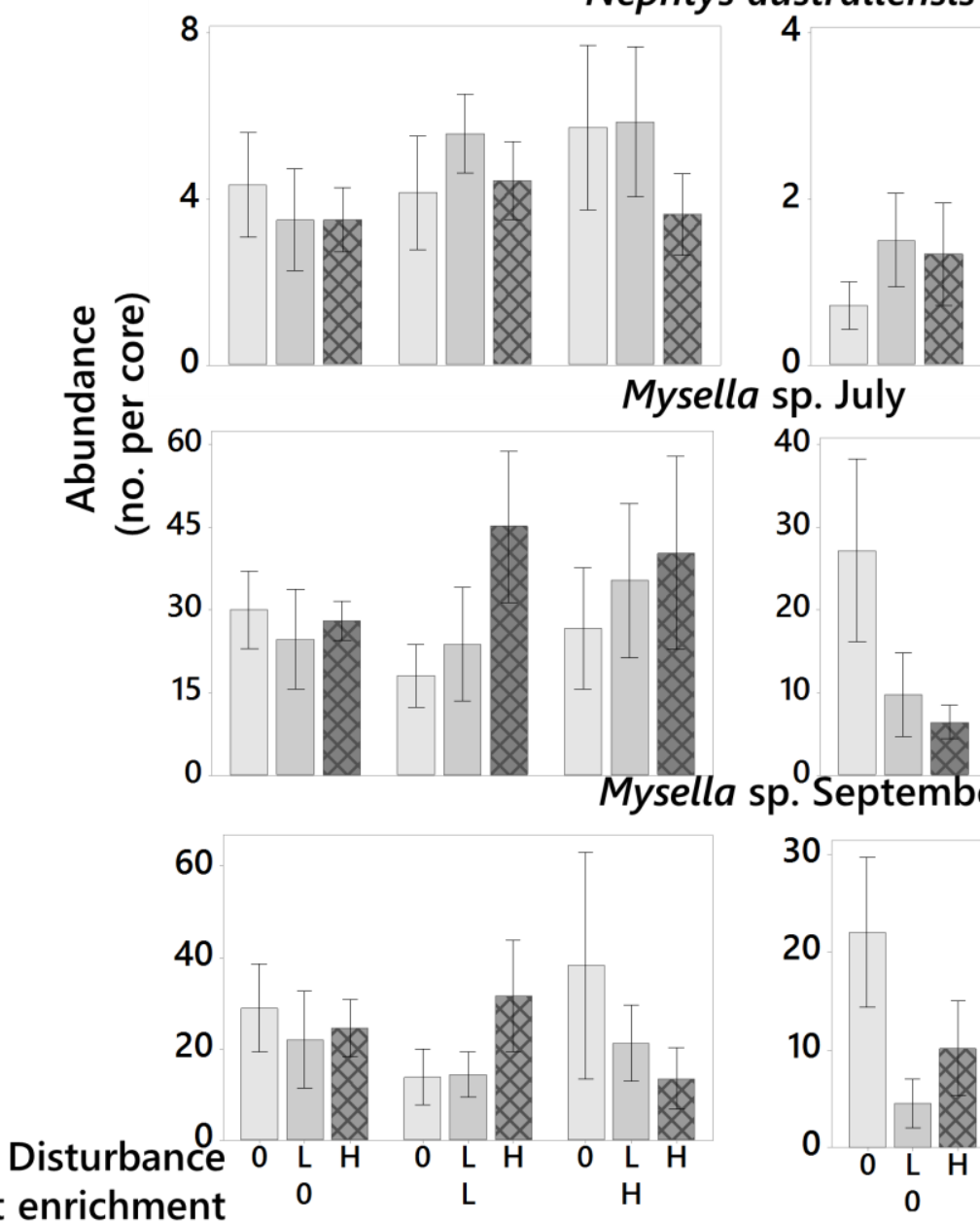

$$
0
$$

2

Mysella sp. July

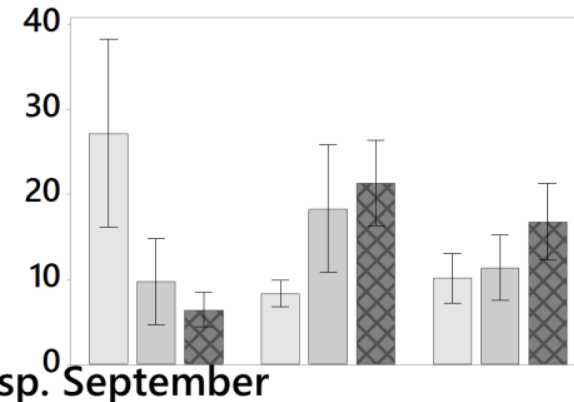

Mysella sp. September

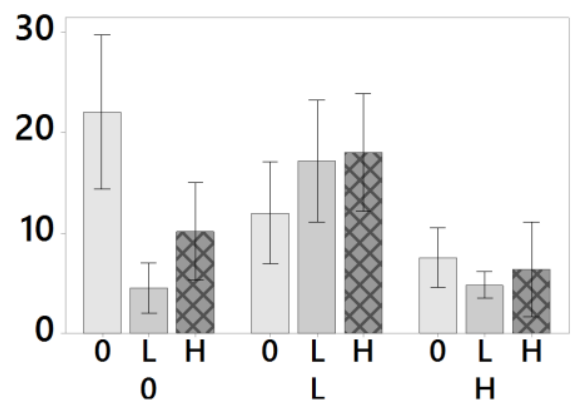

Figure 4:

805 
A)

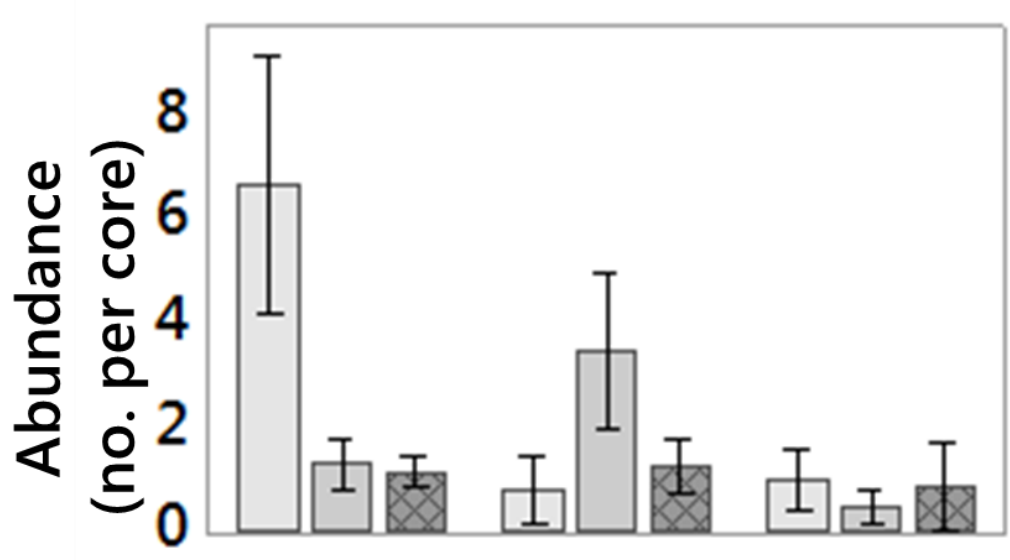

B)

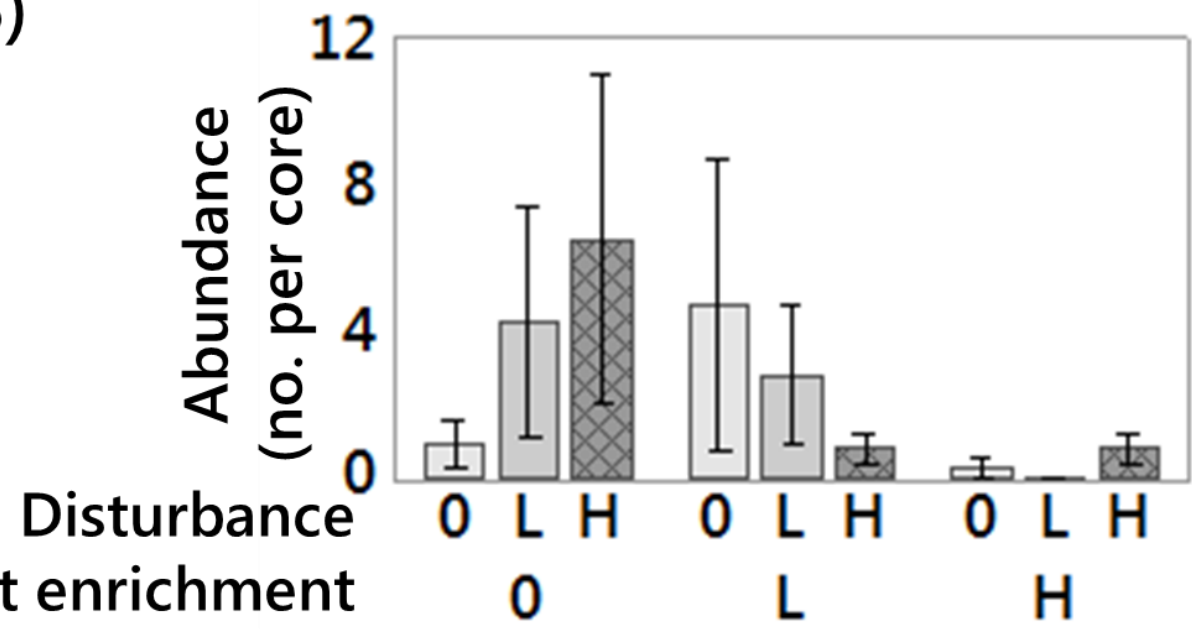

807

Nutrient enrichment

808 Figure 5:

809 